\title{
Informal networks in tourism publishing
}

\author{
Anita Zehrer ${ }^{1}$ and Harald Pechlaner ${ }^{2 *}$ \\ Received: 03/06/2009 Accepted: 24/02/2010
}

\begin{abstract}
${ }^{1}$ Department of Tourism and Leisure, Management Center Innsbruck (MCl), Weiherburggasse 8, Austria; phone: +43 05122070 3332, fax: +43 05122070 3399, email: anita.zehrer@mci.edu

${ }^{2}$ Catholic University of Eichstaett-Ingolstadt, Pater-Philipp-Jeningen-Platz 2, 85072 Eichstaett, Germany; phone: +49 842193 1185, fax: +49 84219321 85, email: harald.pechlaner@ku-eichstaett.de

* Corresponding author
\end{abstract}

\begin{abstract}
Greater size and complexity of research activities lead to a higher need for collaboration, which has been reflected in the formation of social relationships in the form of research coalitions and collaborative research networks in the past decades. This is an empirical paper that explores the pertinent issues of informal networks in tourism publishing. The paper undertakes a thorough review of the relevant literature before developing propositions regarding collaborative activities of tourism researchers. To empirically test how and why researchers collaborate, a web-based electronic study was carried out asking members of international scientific tourism organizations about their collaboration activities. Findings reveal that tourism researchers collaborate mainly for accessing expertise and for working efficiently.
\end{abstract}

(c) 2010 International University College. All rights reserved

Keywords: informal networks, invisible colleges, tourism publishing

Citation: Zehrer, A., H. Pechlaner (2010) Informal networks in tourism publishing. European Journal of Tourism Research 3(1), pp. 23-37

\section{Introduction}

The greatest transformation in the organization of scientific work is the orientation on largescale projects, or 'big science'. As Price revealed already in 1986, greater size and complexity of research activities have lead to a higher need for collaboration, which has been reflected in the formation of social relationships in the form of research coalitions and collaborative research networks (Shrum et al., 2007). The trend towards collaboration seems to be independent of discipline.

Today, science is regarded as a collaborative enterprise (Finholt, 2003). Watts in 2003 states that "in the quiet corridors of academia ... a new science has been emerging - one that speaks directly to the momentous events going on around it. For want of a better term, we call this new science the science of networks" (Watts, 2003, p. 13). Several sociological studies of modern science and the communication patterns of scientists agree that the form of organization which has become most known are 'invisible colleges'" (Macharzina, Wolf and Rohn, 2004, p. 337). The name derives historically from a group of people in the mid-seventeenth century who later formally organized themselves into the Royal Society of London. The people in such a 
group claim to be reasonably in touch with everyone else who is contributing materially to research in this subject. However, the question is if it does require five, six or seven co-authors to produce a quality article.

The objective of the present study is to establish an understanding of informal networks and collaboration motives of academics. The paper is exploratory in nature and takes an empirical approach. Following this introduction, the paper undertakes a review of the relevant literature regarding: (i) the science of networks; (ii) invisible colleges; (iii) informal networks; (iv) networks in journal publishing; and ( $v$ ) cooperation motives. The paper then elaborates a series of propositions regarding the nature of collaboration activities and potential motives for collaboration among researchers. To empirically test how researchers collaborate, a web-based electronic study was carried out in 2005 asking members of international scientific tourism organizations on their collaboration activities. The paper summarizes major findings of the study and concludes with its limitations and future research opportunities.

\section{Literature review}

\subsection{The Science of Networks}

Complex cooperation relations are usually called 'networks'. "In the network approach to social structure, the social positions of actors are revealed by the actors' patterns of relations with other actors, and a differentiated social structure is defined by the existence of actors who occupy different positions in networks of social relations" (Friedkin and Johnsen, 1997, p. 209). A substantial amount of work by network analysts has been concerned with understanding "how social structure affects individual 'exchange' or 'transitional' behaviour" (Uehara, 1990, p. 528). In the beginning, networks were connections of machines, yet the more differentiated they became the more social linkages were conveyed. The network has evolved in four contexts (Herman, 2003; Jackson and Wolinsky, 2003; Dutta and Mutuswami, 2003). (1) Sociology - in analyzing organisations, networks reflect the entity of channels existing within a group and its composition. (2) Technology - the technological network is the entity of telecommunication lines which are interconnected. (3) Economy - a network represents the entity of principally stable relationships existing among various partners with regard to a strategic or economic object. (4) Management - management is often regarded as a network of employees and external persons.

In the last few years, research on network structures grew. "Collaboration in science is not recent; it ... has increased rapidly during the past decades" (Luukkonnen et al., 1993, p. 15). Laudel (2001, p. 763) assumes that "one of the most important changes scientific research has undergone in the $20^{\text {th }}$ century is the change from being something undertaken by single individuals into being a chiefly collective enterprise." However, basically, "collaboration between peers (i.e. scientists of similar standing) is more likely than collaboration between individuals of unequal rank..." (Katz and Martin, 1997, p. 5). Hence, science is regarded as a collaborative enterprise that allows researchers to plug into bigger scientific networks (Finholt, 2003; Marsden, 1990). By collaborating with others in another institution or country, researchers can greatly extend their personal network (Katz and Martin, 1997). And, this trend towards collaboration seems to be independent of discipline (Finholt, 2003; Jackson, 2003).

\subsection{Invisible Colleges}

Several sociological studies of modern science and the communication patterns of scientists agree that the form of organization which has become most known are 'invisible colleges' (Macharzina et al., 2004; Luukkonen et al., 1993). The name derives historically from a group of people in the mid-seventeenth century who later formally organized themselves into the Royal Society of London. "...The definition and understanding of the term have varied considerably from writer to writer. The basic phenomenon seems to be that in each of the more actively pursued and highly competitive specialties in the sciences there seems to exist an 'in-group'. The people in such a group claim to be reasonably in touch with everyone else who is contributing materially to research in this subject... The body of people meet in select 
conferences ... they commute between one centre and another, they circulate preprints and reprints to each other, and they collaborate in research" (Price, 1986, p. 119). One can therefore conclude that in each of the more actively pursued and highly competitive specialities in the sciences there seems to exist an 'in-group'.

Invisible colleges can be regarded as ingroups. "A group is a social system with its own hierarchy of interlocking roles. Ideally, within this structure, group members display regular contact; cooperatively interact with one another; and share a common goal, common norms, and a sense of belonging" (Hanna and Wozniak, 2001, p. 338). Invisible colleges can be regarded as a "form of network and represent a good source of potential collaborators" (Katz and Martin, 1997, p. 5). Hence, researchers in any academic discipline tend to cluster into informal networks, or 'invisible colleges'. As invisible colleges seem to be an informal social phenomenon of communication relations among interacting researchers and scholars in a specific discipline who share some common interest, it is assumed that an invisible college is not rooted in a formal institutional structure. Researchers or scholars are regarded as social actors who make use of the invisible college in terms of information seeking, sharing patterns, collegiality or collegial interaction. Moreover, invisible colleges are a temporary network with no hierarchy and no vertical integration, fluid and flexible. "Invisible colleges are usually defined as held together by informal interactions" (Persson and Beckmann, 1995, p. 352). However, this phenomenon is largely known only from personal histories and interviews, i.e., so far there has never been an objective analysis of an invisible college structure by any other means than personal story-telling and although scientists have many contacts with other scientists, invisible colleges are difficult to prove.

\subsection{Informal Networks}

Besides formal networks, informal networks exist. "[P]articipants in the larger 'open science' community ... might expect the same level of cooperative-information sharing, and exchanges of research materials, [but] in the absence of a formal collaborative arrangement" (David and Keely, 2003, p. 94). According to Katz and Martin (1997), most collaboration starts informally and often derives from informal conversation. Informal communication may then result in increasing cooperation commitment.

Informal networks are the web of relationships that people use to exchange resources and services; they are distinct from formal networks in that they are not officially recognized or mandated by organizations and in that the content of their exchanges can be work-related, personal, or social. "Informal networks can be defined as networks where individuals are connected based on their social or personal relationships rather than work or task related relationships. ... By nature, informal networks are highly dynamic and are difficult to identify. Players in informal networks are identified as nodes that keep networks alive by their links with other nodes" (Awazu, 2004, p. 2).

Informal networks are generally differentiated into 'strong ties' and 'weak ties' (Fairchild and Robinson, 2004; Kadushin, 2002). Informal networks which are characterized by actors, who are related to each other by a network, which for instance builds on similar attitudes, values or social status, are 'strong ties'. Strong ties are characterized by "(a) a sense that the relationship is intimate and special, with a voluntary investment in the tie and a desire for companionship with the partner; (b) an interest in frequent interactions in multiple contexts; and (c) a sense of mutuality of the relationship, with the partner's needs known and supported" (Walker et al., 1994, p. 57). 'Weak ties', on the contrary, are characterized by heterogeneous actors and involve fewer, less intimate exchanges; they maintain infrequently, with individual's experiences and exposures operating in a different sphere. Weak ties are more likely to link members of different small groups than are strong ones, which tend to concentrate within particular groups. While 'strong ties' benefit the development of socioemotional relationships, which may convey solidarity, confidence and security, 'weak ties' have a big advantage in terms of information 
transfer. While 'strong ties' aim at building a coherent community, 'weak ties' focus on target-oriented relationships in terms of projectsupported co-operations. An individual's weak ties will make more unique connections to others for the individual than that individual's strong ties (Fairchild and Robinson, 2004). Basically, it can be said that the existence of 'weak ties' benefits the strengthening of purpose-oriented 'strong ties'.

\subsection{Networks in Journal Publishing}

There are a number of definitions of 'networks' in several disciplines. These definitions differ in terms of network variety. Basically, the term 'network' is often defined as "a specific set of linkages among a defined set of actors, with the additional property that the characteristics of these linkages as a whole may be used to interpret social behaviour of the actors involved" (Mitchell, 1969, p. 2; Van der Duim, 2007; Watts, 2003). Therefore it can be stated that the key to networking is to create new information in an efficient manner. This paper uses a rather general definition of the term network as the structure of ties among the actors in a social system; these ties may be based on a range of connectors such as conversation, friendship, academic exchange or information exchange (Nohria \& Eccles, 1992).

Research collaboration is generally seen as a response to specialization and competition in science. Scientific collaboration usually arises out of relationships among researchers where shared interests in a specific research problem are discovered (Katz, 1994). This might start as an informal relationship where researchers work together to enrich the field with their combined insights (Bozeman, 2004; Hafernik et al., 1997). Interactions with other scientists promote the exchange of information and provide mutual stimulation (Laudel, 2001). Especially in publishing scientific articles, networks of scientists are formed. In this context, Finholt (2003, p. 5) speaks of collaboratories, which are defined as "a laboratory without walls, where scientists are connected to each other, to instruments, and to data independent of time and location. .... It is a hybrid of collaborate and laboratory."
Effectively, research networking is hierarchical in nature. At the lowest level is networking in one's own institution, and then networking at regional level, then at national level and, finally, at international level (Law and Chon, 2007). "Academics feel most comfortable with individuals they know well and with whom they are in frequent contact" (Jones et al., 1996, p. 610; McKecher et al., 2006; McKercher, 2005; Ryan, 2005; Page, 2003; Wade and Tampubolon, 2002). Historically, joint intellectual activity depends on physical proximity. However, on the collective scale this means that co-location involves exclusion from those who are located elsewhere (Finholt, 2003).

In McKercher's study of prolific authors in tourism and hospitality (2006), it was found that the world's most prolific authors like to coauthor. Two scientists are considered connected if they have authored a paper together; this seems a reasonable definition of scientific acquaintance: most people who have written a paper together will know one another quite well. Royle et al. (2007) investigated collaboration in journal publishing in China and found out that China is involved in international collaboration with $49 \%$ of articles that are a result of Chinese international collaboration. Hence, while it is often difficult to see what an author has truly done in a specific paper, it may be easier and more informative to examine one's overall co-authorship behaviour across one's whole publication record (Newman, 2001; Woods, 1998; Sheldon, 1991). Shrum et al. (2007) compare collaboration across specialities and reach empirically based conclusions about their characteristics, evolutions, and outcomes across several areas of disciplines. David and Keely (2003) present a model in order to shed light on how research networks self-organized themselves. Newman (2004) e.g. used data from three bibliographic databases in biology, physics, and mathematics and constructed networks deduced from the pattern of co-authorships of papers. Hartley et al. (2001) explored the publishing activity among economists to measure the productivity of economists in joint publishing. Already in 1992 Luukkonen et al. undertook time-series to understand patterns of 
international scientific collaboration and found out that differences in the propensity of countries to collaborate internationally could be explained partly by their intellectual influence. "The less developed the scientific infrastructure of a given country, the higher the tendency for international co-authorship collaboration" (Luukkonen et al., 1992, p. 123).

\subsection{Cooperation Motives}

The question why international collaboration on scientific papers is formed relates to a number of factors closely related to the nationality of the scientist including geographic locale, and linguistic, cultural and political factors (Law and Chon, 2007; McKecher et al., 2006; Page, 2003). According to Pierce and Garven (1995, p. 70), "accessibility to other researchers is an important consideration to those wishing to add to their citation record or engage in scholarly dialogue."

While in former days collaboration was regarded to be a mechanism for gaining access to recognition in the professional community, today cooperative research mainly results due to time constraints (Kadushin, 2002). Another motive for collaboration is to overcome barriers with cross-sectional collaboration becoming more ostensible (Bozeman, 2004). According to Hafernik et al. (1997) collaborating on research and writing projects enriches the personal and professional lives and helps to make contributions to research institutions, to the profession of a scientist, and to the academic community. Another motivation for researchers to collaborate may be to get started on projects. David and Keely (2003) for instance present a model in order to shed light on how research units self-organize into coalitions when seeking funding for proposed projects. Furthermore, collaboration provides a built-in support system for the researcher; it promotes clearer and better writing as two or three pairs of eyes see more than one (Beaver, 2001). Burnett and Ewald (1994) believe that collaborative groups, by their very nature, have the potential advantage of offering multiple perspectives, which can contribute to shaping a more complete view of any situation. Hafernik (1997, p. 34f) agrees that "colleagues can encourage each other in all their projects, not just their shared ones, and can provide editorial and other advice."

\section{Empirical study}

\subsection{Methodology}

Based on theoretical findings on research collaboration and motives for cooperation, a study was carried out among tourism researchers. The aim was to test the following research question: In how far do scientists collaborate when it comes to journal publishing in the field of tourism?

The study took place in a one-month period, from February $22^{\text {nd }}$ to March $22^{\text {nd }} 2005$ among members of tourism-related scientific organizations and made use of a selfadministered standardized questionnaire. A total of 2,113 members of five tourism-related associations (AIEST ATLAS, CIRET, IAST, and IFITT) ${ }^{1}$ were asked to fill in the questionnaire. Organizations were selected because they are well-established, reputable and representative of the tourism field's image of researchers (and practitioners) world-wide, as well as being readily accessible lists (the lack of a list like PATA may result in suppressing some of the South-East Asian region, but the ATLAS list is arguably diverse with respect to geographical distribution and gender of list members, so the sample was stratified). While ATLAS members were reached via a list-mail spread to all members, and IFITT members were contacted by the IFITT secretariat, AIEST, IAST and CIRET members were contacted personally via e-mail as the addresses were provided by the organizations. Double entries (scientist being members of more than one organization) were accepted in the sample, as it was not of prime importance to investigate collaboration among these scientific organizations but among each individual scientist. The study at hand made use of an email containing a link to the survey website (web-based survey), as it was considered to be an appropriate means of soliciting a response to the survey because of the generally high use of the electronic mail by academics.

On the basis of the findings of the literature review, this paper puts forward a series of propositions regarding cooperation activities for 
joint publishing of researchers in tourism.

P1: Researchers in the tourism field often collaborate for joint publishing in journals.

As already stated in the literature, greater size and complexity of research activities lead to a trend for collaboration (Finholt, 2003). Collaborating is seen as a response to specialization in science as researchers share interests in a specific research problem or field.

\section{P2: Cooperation arises from informal} relationships among researchers.

Networks of co-operations or relationships could be called 'research clusters', as primarily researchers of a particular scientific field are interacting with each other. According to Katz and Martin (1997), most collaboration starts from informal conversations which may then result in increasing cooperation commitment. Also Jones et al. (1996, p. 610) state that "academics feel most comfortable with individuals they know well and with whom they are in frequent contact".

P3: Collaboration in scientific activities is mostly taken for enhancing reputation of a person.

According to literature, different cooperation motives exist. For researchers, publications result in career enhancement, recognition and awards. According to Hafernik et al. (1997) collaborating on research and writing projects enriches the professional life of a researcher and helps to make contributions to research institutions.

P4: Coalitions in publishing are founded in order to receive funding for proposed projects.

David and Keely (2003) present a model in order to shed light on how research units selforganize into coalitions when seeking funding for proposed projects. Also Mort et al. (2004, p. 52) believe that "research funding and faculty appointment and promotion has become increasingly competitive and the perceived quality of publications is increasingly important" (Beaver, 2001).

P5: Collaboration arises from a desire to avoid isolation in research activities.

Burnett and Ewald (1994, p. 44) believe that "collaborative groups, by their very nature, have the potential advantage of offering multiple perspectives, which can contribute to shaping a more complete view of any situation. Collaborative groups also bring together a critical mass of expertise that is unlikely to be found in a single individual; a project benefits from new information and insights, from differing theoretical stances." Fox and Faver (1984) already stated in the eighties that collaboration might also arise primarily form a desire to avoid isolation in research activities, and may furthermore enhance collective creativity.

P6: Collaboration helps to access specific know-how.

Knowledge flows through and across networks. "[C]ollaboration itself is a mechanism for knowledge transfers that requires coparticipation in the research itself, because of the difficulties of contracting for 'know-how' that remains imperfectly codified, and in some instances is not even articulated by the agents that possess and make use of the necessary knowledge. The collaboration is thus valued as creating a 'learning environment' where asymmetric knowledge can be exchanged" (David \& Keely, 2003, p. 94).

The questionnaire form listed eleven closed questions on collaboration activities of researchers and motives for collaboration. Closed questions were chosen for the questionnaire as they clearly have their advantages. The respondents were offered a full range of responses to eliminate the possibility of bias which can arise when respondents have a limited number of options from which to choose. According to May (1993), answers met two conditions: they were exhaustive and mutually exclusive. All questions in the questionnaire at hand were closed questions, however, with the possibility to add and then rate e.g. further motives for collaboration in case the list was not exhaustive for the respondent.

The questionnaire at hand made use of a rating scale in order to provide a straightforward way of asking attitudinal information. A number of forms of rating scales have been developed for attitudinal information with Likert and semantic differential scales being the most common. A Likert item is simply a statement which the 
respondent is asked to evaluate according to any kind of criteria. Basically, the level of agreement or disagreement is measured. Likert scaling is a bipolar scaling method, measuring either positive or negative responses to a statement. The semantic differential scale is a bipolar rating scale, too. "Semantic differential differs from Likert scale in that opposite statements of the dimension are placed at the two ends of the scale and respondents are asked to indicate which they most agree with by placing a mark along the scale" (Brace, 2008 , p. 76). In our case, a balanced five-level Likert scale ranging from 1=very important/frequently to $5=$ very unimportant/ never was used to answer the questions. Although, Likert scales receive wide range of acceptance, authors are well aware that the popularity of Likert scales are not without controversy and criticized regarding the measurement scale, dimensionality, and confusion of the neutral choice. Sometimes for instance a four-point scale is used, which is a forced choice method since the middle option of "neither agree nor disagree" is not available (Albaum, 1997). It seems as if eliminating the middle neutral point does increase the commitment of respondents to be either positive or negative.

Authors however used a five-point scale to provide the middle option of a neutral or indifferent answer as it was found that it is appropriate for the particular research question and subject matter. Moreover, comparability with other studies was a deciding factor, too.

\subsection{Study Results}

The SPSS statistics are used for data analysis. A total of $n=150$ completed questionnaires were received, which is equivalent to a response rate of $7.10 \%$. Most of the respondents are between 31 and 40 (32.0\%). 109 respondents are male, 40 female (1 response missing). As far as the country of residence is concerned, respondents from 32 countries filled in the questionnaire. If the numbers are attributed to the five continents, it can be seen that the majority of interviewees are from European countries (62.7\%), followed by the United States (17.4\%), 8\% were responding from Africa, $7.3 \%$ from Australia and $4.7 \%$ from Asia. The position of the respondents clearly shows that $92.7 \%$ of all interviewees are Academic Staff with 46.2\% being Full Professors, 29\% being Associate Professors and $24.8 \%$ being Assistant Professors. It is generally agreed that most researchers are members not only of one but more scientific organizations (table 1). Most of the interviewees are members of AIEST $(n=59)$, ATLAS $(n=53)$ and TTRA $(n=33)$, with 18 being members of both AIEST and TTRA, 12 persons indicated double-membership in ATLAS and AIEST.

\section{Table 1: Membership Overview}

Memberships

\begin{tabular}{c|ccccccc}
\hline \hline & TTRA & AIEST & ATLAS & IFITT & CIRET & IAST & CAUTHE \\
\hline TTRA & 33 & 18 & 10 & 4 & 5 & 9 & 3 \\
AIEST & 18 & 59 & 12 & 9 & 9 & 8 & 1 \\
ATLAS & 10 & 12 & 53 & 6 & 9 & 2 & 2 \\
IFITT & 4 & 9 & 6 & 28 & 4 & 0 & 0 \\
CIRET & 5 & 9 & 9 & 4 & 19 & 3 & 2 \\
IAST & 9 & 8 & 2 & 0 & 3 & 13 & 1 \\
CAUTHE & 3 & 1 & 2 & 0 & 2 & 1 & 6
\end{tabular}


First, experts were asked about the amount of collaboration activities they do have when it comes to publish research in tourism journals. A five-point Likert scale was used ranging from 1 =frequently to $5=$ never. As the following table shows, the majority of the tourism experts indicate that they are frequently (25\%), often (27.1\%) or sometimes (27.1\%) collaborating with other researchers for joint publishing./

Another question asked about the level of collaboration, in terms of international, national, regional and local collaboration. The results obtained show that $6.3 \%$ are collaborating internationally, $37.5 \%$ nationally, $\quad 15.6 \%$ regionally and $40.6 \%$ locally. These results show that tourism researchers often collaborate for joint publishing at different levels (on a national, regional and local level).

P1: Researchers in the tourism field very often collaborate for joint publishing in journals.

This proposition could not be falsified.

Then, experts were asked with what kind of persons they mostly collaborate with. Again, a 5 -point Likert scale was used ranging from $1=$ very much to $5=$ not at all. The outcome (figure 2) shows that the majority of the experts asked are collaborating with other colleagues when these cover a specific field of research or when they personally know them.

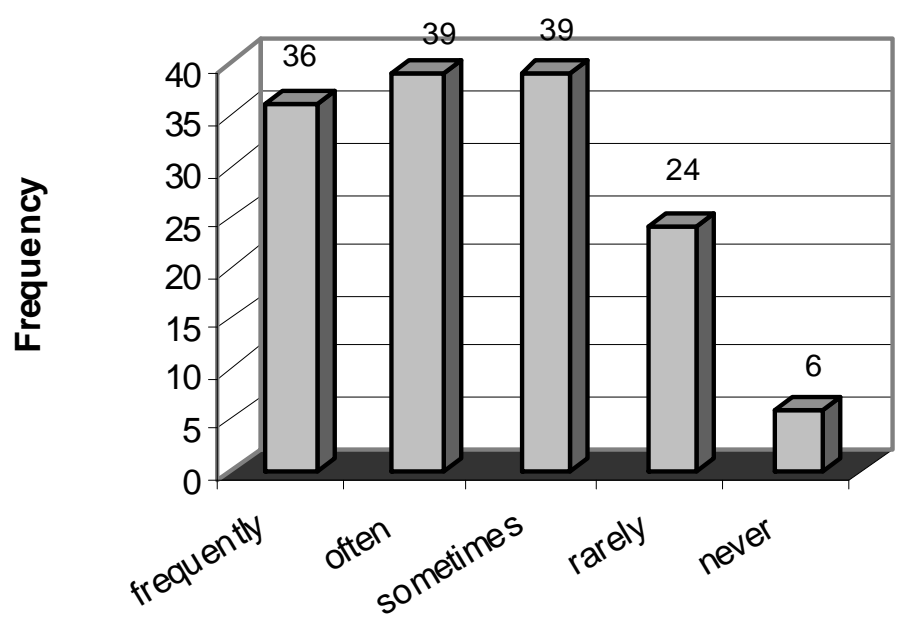

Figure 1: Amount of Collaboration $n=144$

Figure 2: Collaborating Person

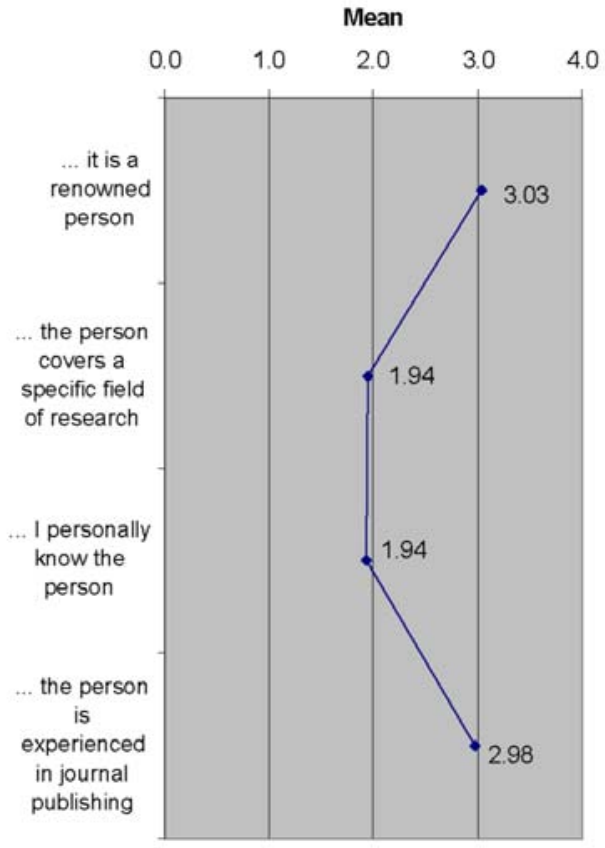


Therefore, proposition 2 cannot be falsified. Cooperative activities in joint publishing in the tourism related disciplines mainly arise from informal acquaintances of researchers.

P2: Cooperation arises from informal relationships among researchers.

This proposition could not be falsified

Furthermore, authors were interested in the motives for which researchers collaborate in tourism research (5-point Likert scale ranging from 1=very important to $5=$ very unimportant). The outcome shows that the majority of experts collaborate for accessing expertise of colleagues (2.20), for efficiency (2.30) and for productivity reasons (2.36). On the contrary, motives such as the accessibility to funding (3.15), to reduce isolation (3.18), and professional advancement (3.26) are not very important for experts as a reason for collaboration when it comes to joint publishing.

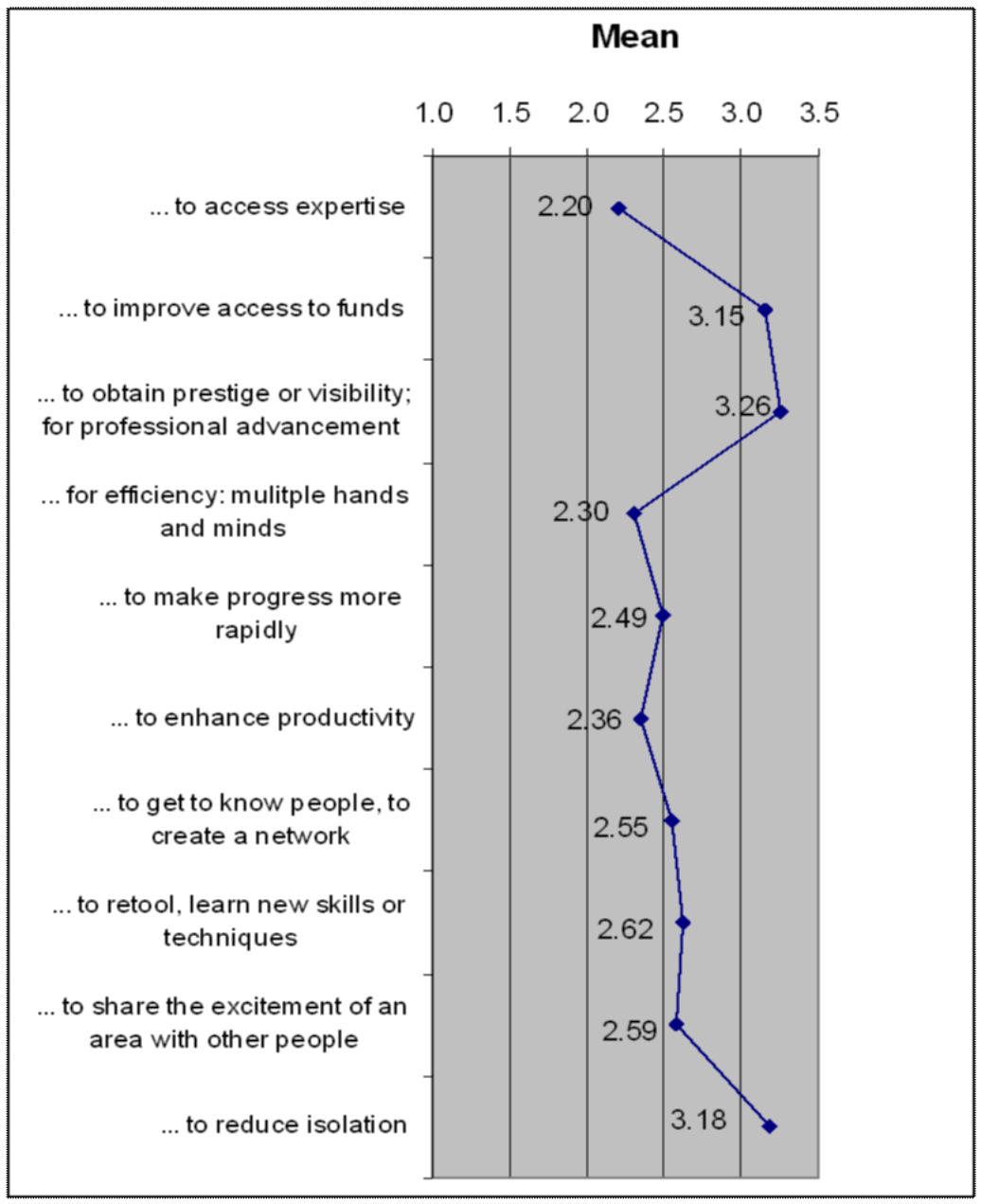

Figure 3: Collaboration Motives 


\section{Table 2: Rotated Component Matrix}

\begin{tabular}{|l|r|r|r|}
\hline \multicolumn{1}{|c|}{ Motives } & \multicolumn{2}{|c|}{ Factors } \\
\cline { 2 - 4 } & $\begin{array}{c}\text { Enhance } \\
\text { knowledge }\end{array}$ & $\begin{array}{l}\text { Improve } \\
\text { production }\end{array}$ & $\begin{array}{c}\text { Obtain } \\
\text { prestige } \\
\text { \& funding }\end{array}$ \\
\hline$\ldots$ to share the excitement of an area with other people & 0.837 & & \\
\hline$\ldots$ to retool, learn new skills or techniques & 0.799 & & \\
\hline$\ldots$ to get to know people, to create a network & 0.792 & & \\
\hline$\ldots$ to reduce is olation & 0.780 & & \\
\hline$\ldots$ for efficiency: multiple hands and minds & & 0.859 & \\
\hline$\ldots$ to make progress more rapidly & & 0.826 & \\
\hline$\ldots$ to enhance productivity & & 0.813 & \\
\hline$\ldots$ to access expertise & & 0.530 & 0.463 \\
\hline$\ldots$ to improve access to funds & & & 0.871 \\
\hline$\ldots$ to obtain prestige or visibility; for professional & & 0.845 \\
\hline advancement & & & \\
\hline
\end{tabular}

\begin{tabular}{|l|l|}
\hline Propositions & Status \\
\hline $\begin{array}{l}\text { P3: Collaboration in scientific activities is mostly } \\
\text { taken for enhancing reputation of a perso } \mathrm{r}\end{array}$ & Falsified (mean = 3.26) \\
\hline \begin{tabular}{l|l|} 
P4: Coalitions in publishing are founded in order to \\
receive funding for proposed projects.
\end{tabular} & Falsified (mean = 3.15) \\
\hline $\begin{array}{l}\text { P5: Collaboration arises from a desire to avoid } \\
\text { isolation in research activities. }\end{array}$ & Falsified (mean $=3.18)$ \\
\hline $\begin{array}{l}\text { P6: Collaboration helps to access specific know- } \\
\text { how. }\end{array}$ & Not falsified (mean=2.20) \\
\hline
\end{tabular}

The summary of tested propositions on collaboration motives of tourism researchers looks as follows:

Based on the list of motives respondents were asked to rate, factor analysis was used to find latent factors among observed variables. The extraction method is a Principal Component Analysis and Rotation Method Varimax Rotation with Kaiser Normalization. Table 2 shows the revealed factors (rotated component matrix), indicating the total variance explained and also the Kaiser-Meyer-Olkin (KMO) Test. $^{2}$ The Kaiser-Meyer-Olkin (KMO) Test measuring the sampling adequacy showed a sound value of 0.835 . Total variance explained amounted to $74.797 \%$ (see table 2). Cronbach's Alpha for the ten factors is 0.886 .

The values which are associated with the motives for cooperating may be represented by three factors. Variables with higher loadings are considered more important and have greater influence on the label selected to represent a factor. While factor 1 "Knowledge Enhancement" comprises the personal contact and information gathering resulting from collaboration, i.e. "... to share the excitement of an area with other people", "... to retool, learn new skills or techniques", "... to get to know people, to create a network", and "to reduce 
isolation", factor 2 "Improve Production" reflects factors improving the production of a scientist in terms of the number of publications gained through collaboration activities, like "... for efficiency: multiple hands and minds", "... to enhance productivity", and "... to access expertise". Factor 3 "Obtain Prestige \& Funding" comprises factors which related to the personal academic career of scientists and the funding of research projects, and comprises "... to improve access to funds" and "...to obtain prestige or visibility, for professional advancement."

Comparing the results of this study with similar empirical studies on this topic, the following picture becomes apparent. "Knowledge Enhancement" was identified as the most important reason for cooperating in journal publishing with other researchers. This already was indicated by the works of David and Keely (2003). It is interesting to see that factor no. 2, 'improve production' is also widely discussed in literature with the productivity of a scholar being often considered a substitute measure of a scientists' quality (Parker et al., 1998). Katz and Martin conclude that "...scientific output as measured by publications is closely dependent on the frequency of collaboration among authors. The nature of the effect on productivity depends on the type of links; while collaboration with high-productivity scientists tends to increase personal productivity, collaboration with low-productivity scientists generally decreases it" (Katz \& Martin, 1997, p. 5). As far as prestige and funding as a collaboration motive is concerned, important career and tenure decisions as well as the allocation of research funding commonly depend on these necessarily imperfect judgments about the quality of a scientist's research, which in turn depends on his publication record (Mort et al., 2004; Beaver, 2001; Hafernik et al., 1997). This argument is also strengthened by Korobkin (1999, p. 857) by stating that "authors derive prestige in the scholarly and legal communities based partly on the placement of their journal articles."

\section{Conclusions and implications}

The scientist goes through a range of stages in his career as a researcher and makes use of the journal as an instrument for publishing his findings; publishing one's research findings is crucial to the career procedure. The formation of informal networks is an essential prerequisite for success in research, what the results largely substantiate. Consumer behaviour of scientists is not only determined through the relationship between customer and provider (author and editor), but through the relationships among the consumers (invisible colleges). As every system has its environment, the environment of the journal is the scientific community by which it is surrounded.

Results show that science in tourism seems to be a collaboration industry (Finholt, 2003). The majority of the tourism experts indicate that they are frequently (25\%) or often $(27.1 \%)$ collaborating with other researchers for joint publishing, whereas $6.3 \%$ of this type of collaboration is international, $37.5 \%$ national, $15.6 \%$ regional and $40.6 \%$ local. This indicates the importance of joint and even multidisciplinary article publishing for one's academic career. Shrum et al. (2007) e.g. collected an empirical base of $n=600$ researchers for understanding collaboration among scientists.

As far as the type of person is concerned with whom experts collaborate, the majority of the experts is looking for scientists which cover a specific field of research on which they presume to publish or collaborate with friends and personal acquaintances whom they already know, which confirms the general opinion that collaboration starts on an informal basis (Fairchild and Robinson, 2004).

The most important motives for collaborating are access of expertise (2.20), efficiency (2.30) and productivity issues (2.36). This is an interesting finding, as according to Kadushin (2002), today cooperative research mainly results due to time constraints of researchers, who believe that joint publishing is done faster than writing a single-authored paper. 
As far as theoretical implications are concerned, it can be stated that the whole journal system could be regarded as a network of actors. It becomes apparent that a number of theories exist to approach scientific collaboration in terms of journal publishing and/or to base the perception of collaborations on different theoretical backgrounds. However, to date, no comprehensive theory of scientific collaboration exists (Shrum et al. 2007). The reason for this might be that a serious limit on co-authorship data is that it does not generate insights into the internal dynamics of collaborations. In this regard, the findings of this study might stimulate to discuss future theories to approach scientific networks.

As far as practical implications are concerned, it can be derived from the results of the study that academics tend to collaborate for the purpose of publishing articles together and therefore communicate and collaborate in 'invisible colleges'. This implies that networking is essential in academia to enhance one's career, to be linked to colleagues and to be well informed. Collaboration might therefore have a practical implication regarding the productivity of researchers and their knowledge increase. It can hence be suggested to network and collaborate in academia particularly to young researchers who are at the beginning of their career.

\section{Limitations}

The present study has certain limitations that need to be taken into account when considering the results of the study and its contributions. The limits of the study can mainly be traced back to the following issues discussed below.

As the target group, scientific tourism organizations were selected, which were thought to be best capable of indicating their collaboration activities when it comes to publishing in scholarly tourism journals due to their familiarity with and experience in publishing. It is generally assumed that experts produce reliable and valid results. But, only limited agreement exists of what really is an expert. In the literature, experts are characterized by their high degree of knowledge and abilities in a specific field. Yet, these thoughts lead to the conclusion that the expert himself is a matter of controversy and should be further discussed and defined. Here, the members of selected scientific organizations were regarded as experts. But, with regard to the many existing scientific organizations, only a very small proportion of the scientific community was surveyed in the empirical study. To conclude, the choice of experts is critical to the perception of collaboration activities. Further research is needed to examine the perception of the many existing types of 'collaborators' for a profound comparison to the results unveiled. The target group for a subject like this is so large that all its members cannot be studied. The study asked members of scientific tourism organizations on their collaboration activities as they are thought to be best able to answer questions on journal publishing, yet produced a small sample size. In a second step, it could be advantageous to ask a more specialized target group, for instance university staff members or even authors of selected journals on their joint publishing strategies. A more specialized group could definitely improve the sample size.

Given the high level of access, and frequent use of email as a communication medium, it was felt that a web-based survey had the advantage of being relatively time-efficient for respondents. Although electronic studies show a wide range of advantages, some disadvantages exist, which are listed in the following lines. (1) Sample demographic limitations, i.e. population and sample limited to those with access to computer and online network. (2) Lower levels of confidentiality, i.e. due to the open nature of most online networks, it is difficult to guarantee anonymity and confidentiality. (3) Layout and presentation issues of a computer questionnaire. (4) Additional orientation/instructions, i.e. more instruction and orientation to the computer online systems may be necessary for respondents to complete the questionnaire. (5) Potential technical problems with hardware and software, computers have a much greater likelihood of 'glitches' than oral or written forms of communication. (6) Response rate, i.e. even though research shows that e-mail response rates are higher, Ryan and Valverde (2003) 
warn that most of these studies found response rates higher only during the first few days; thereafter, the rates were not significantly higher. (6) People can easily quit in the middle of a questionnaire. They are not as likely to complete a long questionnaire on the Web as they would be if talking with a good interviewer. Therefore, the survey instrument has to be seen critically and alternative instruments might become of use in further research.

One more limitation and another research question may include the assessment of any potential difference between those people from developed and developing countries. In the study at hand, no cross-cultural differences were analyzed due to the small sample-size. However, this would have provided insights into inter-cultural collaboration in science.

\section{Further research}

The study aimed at taking a different approach to analyse informal networks in tourism publishing. While colleagues often look at the authorship of journal articles over a period of time to analyze informal network trends across space and time (Law and Chon, 2007; McKecher et al., 2006; McKercher, 2005; Ryan, 2005; Page, 2003), this paper aimed at asking researchers themselves to define networking activities and motives for joint publishing. Further research for instance could consider UCINET or equivalent to map down the identified informal networks. This would also allow seeing how scientists from different cultural backgrounds collaborate with each other.

Altogether, this research has thrown up many thoughts in need of further investigation related to informal networks and collaboration motives of scientist and draws up the following questions: What technical and social mechanisms allow academia to cooperate in research projects, while ensuring mutual benefits? How can network ties be bundled for international cooperation, management, exchange and resolution of research problems among scientists? What are the push and pull factors of informal networks? Moreover, it is challenging to undertake a 'geographic- strategic' cross-national or even crosscontinental know-how analysis: How do scientists make use of know-how? What proportion of know-how is gained from abroad and vice versa, i.e. how much knowledge is transferred to foreign countries? Further research could imply to test the questionnaire predominantly among North American, European and Asian scientists to reveal differences in joint journal publishing. These differences are not only supposed to result from geographical and cultural predispositions, but largely from the differences existing in the understanding and implementation of research. In the literature, it is assumed that the research and publishing behaviour differs among the mentioned nations (Shrum et al., 2007).

Hence, the research has thrown up some questions in need of further investigation and shall stimulate others to carry out research on related issues of science.

\section{Endnotes}

Association Internationale des Études Scientifiques du
Tourisme (International Association of Scientific Experts in
Tourism), Association for Tourism and Leisure Education,
International Center for Research and Study in Tourism,
International Academy for the Study of Tourism,
International Federation for IT and Travel \& Tourism
2 The measure of sampling adequacy should be above 5.3
(Hair et al., 1995, p. 99)

\section{References}

Albaum, G. (1997) The Likert Scale Revisited: an Alternate Version. Journal of the Market Research Society 39(2), pp. 331-349.

Awazu, Y. (2004) Knowledge Management in Distributed Environments: Roles of Informal Network Players. Proceedings of the $37^{\text {th }}$ Hawaii International Conference on System Sciences, 1-6.

Beaver, D. (2001) Reflections on scientific collaboration (and its study): past, present and future. Scientometrics 52(3), pp. 365-377.

Bozeman, B. (2004) Scientists' Collaboration Strategies: Implications for Scientific and Technical Human Capital. Research Policy 33(4), pp. 599-616. 
Brace, I. (2008) Questionnaire Design: How to plan, structure and write survey material for effective market research. London: Kogan Page Publishers.

Burnett, R.E., Ewald, H.R. (1994) Rabbit Trails, Ephemera, and other Stories: Feminist Methodology and Collaborative Research. Journal of Advanced Composition 14(1), pp. 2151.

David, P.A., Keely, L.C. (2003) The Endogenous Formation of Scientific Research Coalitions. Economics of Innovation and New Technology 12(1), pp. 93-116.

Dutta, B., Mutuswami, S. (2003) Stable Networks. In Dutta, B., Jackson, M.O. (eds.), Networks and Groups. Models of Strategic Formation. Berlin [et al.]: Springer. pp. 79-98.

Fairchild, G.B., Robinson, J.A. (2004) It's What You Know and Who They Know: Weak Ties and Strong Ties in Urban Labor Markets. Academy of Management Best Conference Paper 2004 GDO: G1, pp. 1-6.

Finholt, T.A. (2003) Collaboratories as a New Form of Scientific Organization. Economics of Innovation and New Technology 12(1), pp. 5-25.

Fox, M.F., Faver, C.A. (1984) Independence and Cooperation in Research: The Motivations and Costs of Collaboration. The Journal of Higher Education 55(3), pp. 347-359.

Friedkin, N.E., Johnsen, E.C. (1997) Social Positions in Influence Networks. Social Networks 19(3), pp. 209-222.

Hafernik, J.J., Messerschmitt, D.S., Vandrick, S. (1997) Collaborative Research: Why and How? Educational Researcher 26(9), pp. 31-35.

Hair, J.F., Anderson, R.E., Tatham, R.L., Black, W.C. (1995) Multivariate Data Analysis. Upper Saddle River: Prentice-Hall Inc.

Hartley, J.E., Monks, J.W., Robinson, M.D. (2001) Economists' Publication Patterns. The American Economist 45(1), pp. 80-85.
Herman, J. (2003) The New Science of Networks. Business Communications Review 33(6), pp. 22-23.

Jackson, M.O. (2003) The Stability and Efficiency of Economic and Social Networks. In Dutta, B., Jackson, M.O. (eds.), Networks and Groups. Models of Strategic Formation. Berlin [et al.]: Springer, pp. 79-98.

Jackson, M.O., Wolinsky, A. (2003) A Strategic Model of Social and Economic Networks. In Dutta, B., Jackson, M.O. (eds.), Networks and Groups. Models of Strategic Formation. Berlin [et al.]: Springer, pp. 23-49.

Jones, M., Brinn, T., Pendlebury, M. (1996) Journal Evaluation Methodologies: A Balanced Response. Omega International Journal Management Science 24(5), pp. 607-612.

Kadushin, C. (2002) The Motivational Foundation of Social Networks. Social Networks 24(1), pp. 77-91.

Katz, J.S. (1994) Geographical Proximity and Scientific Collaboration. Scientometrics 31(1), pp. 31-43.

Katz, J.S., Martin, B.R. (1997) What is 'Research Collaboration'? Research Policy 26(1), pp. 1-18.

Korobkin, R. (1999) Ranking Journals: Some Thoughts on Theory and Methodology. Florida State University Law Review 26(4), pp. 850-874.

Laudel, G. (2001) Collaboration, Creativity and Rewards: Why and How Scientists Collaborate. International Journal of Technology Management 22(7/8), pp. 762-781.

Law, R., Chon, K. (2007) Evaluating Research Performance in Tourism and Hospitality: The Perspective of University Program Heads. Tourism Management 28(5), pp. 1203-1211.

Luukkonen, T., Tijssen, R.J.W., Persson, O., Sivertsen, G. (1993) The Measurement of International Scientific Collaboration. Scientometrics 28(1), pp. 15-36.

Macharzina, K., Wolf, J., Rohn, A. (2004) Quantitative Evaluation of German Research Output in Business 
Administration:

1992-2001.

Management International Review 44(3), pp. 335-359.

Marsden, P.V. (1990) Network Data and Measurement. Annual Review of Sociology 16(1), pp. 435-463.

May, T. (1993) Social Research: Issues, Methods and Process. Buckingham: Open University Press.

McKecher, B., Law, R., Lam, T. (2006) Rating Tourism and Hospitality Journals. Tourism Management 27(6), pp.1235-1252.

McKercher, B. (2005) A Case of Ranking Tourism Journals. Tourism Management 26(5), pp. 649-651.

Mitchell, J.C. (1969) The concept of use of social networks. In Mitchel J.C. (ed.), Social Networks in Urban Situations. Manchester: University of Manchester Press, pp. 1-50.

Mort, G.S., McColl-Kennedy, J.R., Kiel, G., Soutar, G.N. (2004) Perceptions of Marketing Journals by Senior Academics in Australia and New Zealand. Australasian Marketing Journal 12(2), pp. 51-61.

Newman, M.E.J. (2001). The structure of scientific collaboration networks. PNAS, 98(2), pp. 404-409.

Nohria, N., \& Eccles, R.G. (1992). Face-toface: Making Network Organisations Work. In Nohria N., Eccles, R.G. (eds.), Networks \& Organisations Structure, Form \& Action. Cambridge: Harvard Business School Press, pp. 288-307.

Page, S. (2003) Evaluating research performance in tourism: The UK experience. Tourism Management 24, pp. 607-622.

Persson, O., Beckmann, M. (1995) Locating the Network of Interacting Authors in Scientific Specialties. Scientometrics 33(3), pp. 351-366.

Pierce, B., Garven, G. (1995) Publishing International Business Research: A Survey of Leading Journals. Journal of International Business Studies 26(1), pp. 69-85.
Price, D.J. (1986) Little Science, Big Science and Beyond. New York: Columbia University Press.

Royle, J., Coles, L., Williams, D., Evans, P. (2007) Publishing in international journals: An examination of trends in Chinese co-authorship, Scientometrics 71(1), pp. 59-86.

Ryan, C. (2005) The Ranking and Rating of Academics and Journals in Tourism Research. Tourism Management 26(5), pp. 657-662.

Ryan, G., Valverde, M. (2003) Waiting Online: A review and Research Agenda. Internet Research: Electronic Networking Applications and Policy 13(3), pp. 195-205.

Sheldon, P.J. (1991). An authorship analysis of tourism research. Annals of Tourism Research 18(3), pp. 473-484.

Shrum,W., Genuth, J., Chompalov, I. (2007). Structures of scientific collaboration. MIT Press: Cambridge.

Uehara, E. (1990) Dual Exchange Theory, Social Networks, and Informal Social Support. American Journal of Sociology 96(3), pp. 521-557.

Van der Duim, R. (2007) Tourismscapes: an actor-network perspective. Annals of Tourism Research 34(4), pp. 961976.

Wade, S., Tampubolon, G. (2002) Social Capital, Networks and Leisure Consumption. The Sociological Review 50(2), pp. 156-180.

Walker, J., Wasserman, S., Wellman, B. (1994) Statistical Models for Social Support Networks. In Wassermann, S., Galaskiewicz, J. (eds.), Advances in Social Network Analysis. Thousand Oaks: Sage, pp. 53-78.

Watts, U.J. (2003) Six Degrees. The Science of a Connected Age. New York: Norton \& Company Ltd.

Woods, R. H. (1998). Single vs. co-authored and multiple-authored articles: The views of CHRIE educators on their value. Journal of Hospitality \& Tourism Education 10(1), pp. 53-55. 